\title{
Fútbol callejero: um olhar para os processos educativos
}

\author{
Fútbol Callejero: A Look to the Educational Process
}

\author{
Nathan Raphael Varotto \\ Universidade Federal de São Carlos, São Carlos/SP, Brasil \\ Mestrando em Educação, UFSCar \\ varotton@gmail.com
}

Osmar Moreira de Souza Júnior

Universidade Federal de São Carlos, São Carlos/SP, Brasil

Doutor em Educação Física, Unicamp

\begin{abstract}
RESumo: Este estudo foi realizado no projeto de extensão "Vivências em Atividades Diversificadas de Lazer - Mais Que Futebol (VADL-MQF)", com o objetivo de analisar, compreender e descrever os processos educativos que decorrem das relações estabelecidas durante as vivências com o fútbol callejero no projeto de extensão "VADL - MQF". O fútbol callejero propõe regras que o torna diferente do futebol convencional: nas equipes meninas e meninos jogam juntos, não participam árbitros(as) e as partidas se dividem em três tempos. No primeiro tempo, as equipes estabelecem as regras do jogo em conjunto e de maneira consensual, no segundo tempo se joga a partida e no terceiro, todos(as) os(as) jogadores(as) dialogam sobre o desenvolvimento do jogo e se houve respeito às regras acordadas mutuamente. Durante os três tempos o(a) mediador(a) participa facilitando o diálogo e a interação entre as equipes. A pesquisa foi desenvolvida a partir da perspectiva qualitativa, durante a intervenção foram observados quatro encontros entre abril e maio de 2018, de uma turma do período das manhãs de quinta-feira, anotando todas as informações relevantes num diário de campo. Para estabelecer uma compreensão dos dados coletados e anotações sistemáticas registradas em diários de campo, organizamos categorias temáticas. A partir da análise emergiram duas categorias, a saber: a) "Faustinho perguntou" e b) "Ah é bom porque aqui é o único lugar que não somos julgadas por não saber jogar, que nos dão atenção e nos ensinam".
\end{abstract}

Palavras-chave: Fútbol callejero; Processos educativos; Atividades de Extensão.

ABSTRACT: This study was accomplished in the extension project "Experiences in Diversified Leisure Activities - More Than Football (VADL-MQF)". The purpose of this study is the analyze, comprehend and describe the educational processes that result from the relationships established during the experiences with fútbol callejero (FC) in the extension project "VADL - MQF". The FC proposes rules that differs from conventional football such as girls and boys playing together, the absence of referees and three-set matches. In the first set the teams establish the rules of the game together and consensually, in the second set the game is played and in the third set all players gather to talk about the development of the game, checking if the rules mutually agreed during the first set were followed. During all sets the mediator take part in order to promote dialogue and interaction between the teams. The research was developed from a qualitative perspective, during the intervention four meetings were observed between April and May 2018 from a group of Thursday mornings, recording all the relevant information in a field journal. To establish a comprehension of the collected data and systematic notes from the field journal, we organized thematic categories. From the analysis emerged two categories, namely: a) "Faustinho asked" and b) "Ah it is good because this is the only place that we are not judged for not knowing how to play, that we are payed attention and taught to".

KEYwords: Fútbol callejero; Educational process; Extension Project. 


\section{INTRODUÇÃo}

Em acordo com Luiz Gonçalves Junior, Clayton Carmo e Denise Corrêa (2015), entendemos processos educativos da seguinte forma:

[...] ocorrem em uma relação mútua de aprendizagem e não só em uma situação em que um ensina ao outro, tendo como pressuposto fundamental para seu desenvolvimento o diálogo equitativo e a intencionalidade dirigida para a cooperação, superação, o ser mais, demandando autonomia, possibilidade de decisão e de transformação. Tais condições permitem aos envolvidos compreender em contexto, valores e códigos do grupo, da comunidade e da sociedade em que vivem, tendo a possibilidade de refletir criticamente sobre sua própria condição de pertencimento ao mundo com os outros, educando e educando-se, tornando-se pessoa. ${ }^{1}$

A partir desse entendimento o presente estudo foi desenvolvido na Atividade de Extensão ofertada pelo Departamento de Educação Física e Motricidade Humana da Universidade Federal de São Carlos, denominada "Vivências em Atividades Diversificadas de Lazer - Mais que Futebol" (VADL-MQF), o único lugar da cidade de São Carlos que realiza o fútbol callejero, com o objetivo de analisar, compreender e descrever os processos educativos que decorrem da prática do fútbol callejero.

\section{ConteXtualizando o PRojeto “VivênCIAS EM ATIVIDAdes DiVERSIFICADAS DE LAZER”}

A atividade "Vivências em Atividades Diversificadas de Lazer" anteriormente foi realizada a partir de uma parceria entre o Departamento de Educação Física e Motricidade Humana (DEFMH) da UFSCar e o projeto "Campeões na Rua", das Secretarias Municipais de Esportes e Lazer (SMEL) de Cidadania e Assistência Social (SMCAS) da Prefeitura Municipal de São Carlos (PMSC), no bairro Jardim Gonzaga, localizado na cidade de São Carlos-SP. ${ }^{2}$ Com a mudança de gestão da Administração Municipal de São Carlos, em 2013, foram encontradas algumas

\footnotetext{
1 GONÇALVES JUNIOR; CARMOS; CORRÊA. Cicloviagem, lazer e educação ambiental: processos educativos vivenciados na Serra da Canastra, p. 176.

2 SANTOS. Ludicidade, animação cultural e educação: um olhar para o projeto "Vivências em atividades diversificadas de lazer", 2008.
} 
dificuldades para manter a continuidade do Projeto no Jardim Gonzaga, surgindo também a possibilidade de nova parceria. ${ }^{3}$

Desde outubro de 2013 até o momento, realiza-se a parceria entre o Departamento de Educação Física e Motricidade Humana (DEFMH), da UFSCar, e o Projeto "Mais que Futebol: Futebol Socioeducativo", da Associação Desportiva, Educacional e Social dos Metalúrgicos de São Carlos (ADESM), sendo desenvolvidas as atividades no Clube de Campo do Sindicato dos Metalúrgicos, localizado no bairro Santa Felícia, na cidade de São Carlos-SP.

A parceria dos projetos "Vivências em Atividades Diversificadas de Lazer" e "Mais Que Futebol" tem por objetivo contribuir com a formação crítica e cidadã das crianças e adolescentes que frequentam as atividades oferecidas. Para isso, são desenvolvidas diversas experiências junto aos participantes, visando estabelecer relações em que esteja presente uma cultura de paz, resistindo ao assédio do tráfico, educando para e nas relações étnico-raciais, despertando para possibilidades de trabalho e transformação social, a fim de alcançar uma "educação para e pelo lazer", 4 junto às comunidades do Jardim Gonzaga e Santa Felícia, bem como os bairros adjacentes.

Participam do Projeto crianças com idade entre 7 e 17 anos, que em sua maioria moram nos bairros Santa Felícia, onde se localiza o clube, e também dos bairros Gonzaga, Cidade Aracy II, Antenor Garcia, Pacaembu, Monte Carlo, Romeu Tortorelli, Santa Angelina, Iguatemi, Zavaglia e Abdelnur. As atividades são desenvolvidas às terças e quintas-feiras, contando com Música, Fútbol callejero e Natação. 5

A parceria dos projetos VADL-MQF conta com uma equipe multidisciplinar de educadores(as). São estudantes de graduação dos cursos de Educação Física, Pedagogia, Educação Musical, e estudantes da pós-graduação em Educação com formação inicial em Educação Física, Pedagogia, Ciências Sociais e/ou Música.

3 GONÇALVES JUNIOR. Edital de atividades de extensão - Vivências em Atividades Diversificadas de Lazer, 2013.

${ }^{4}$ Marcellino (2000) afirma que o lazer é veículo e objeto da educação e por isso sugere que o lazer envolve educação para e pelo lazer. Veículo porque compreende a educação pelo lazer, no qual as pessoas se educam através dele e Objeto compreende a educação para o lazer, no qual ele próprio é o motivo da educação.

${ }^{5}$ GONÇALVES JUNIOR. Edital de atividades de extensão, 2013. 
Graduandos(as) e Pós-Graduandos(as), ao atuar enquanto educadores(as) no Projeto, experienciam atividades diferenciadas e desenvolvem-se de maneira compartilhada no envolvimento em interações com crianças e adolescentes de comunidades periféricas empobrecidas, tomando contato com realidades sociais, econômicas e culturais diversas, assumindo um comprometimento com a transformação, educando e se educando.

Para embasar a metodologia dos trabalhos com as crianças e adolescentes, são utilizadas as perspectivas da motricidade humana, de Manuel Sérgio, da fenomenologia existencial, de Maurice Merleau-Ponty e da pedagogia dialógica de Paulo Freire, segundo a perspectiva de Luiz Gonçalves Junior. ${ }^{6}$

\section{FÚTBOL CALLEJERO: ORIGEM E METODOLOGIA}

A terminologia espanhola fútbol callejero, que em português pode ser traduzida por "futebol de rua" ou "futebol rueiro" está atrelada a símbolos, fútbol funciona como atração ao esporte mais praticado no mundo e callejero como uma proposição de voltarmos às raízes do futebol. Ou seja, na rua, onde os participantes criavam as suas regras de maneira autônoma, compreendendo um respeito mútuo ao longo das partidas. ${ }^{7}$

A partir da prática do fútbol callejero é possível imprimir olhares para a igualdade de gênero, pois meninas e meninos jogam juntos e em condições iguais, assim como, para alcançar objetivos sociais, de transformação individual e coletiva. ${ }^{8}$

Bastante diverso, portanto, da lógica esportivo-competitiva, ou, mais que isso, esportivizada, ${ }^{9}$ na qual a prática do futebol, e da maior parte dos esportes, é divida por sexo (masculino e feminino), por faixas etárias (infantil, juvenil - sub-

\footnotetext{
${ }^{6}$ GONÇALVES JUNIOR. Edital de atividades de extensão, 2013.

${ }^{7}$ ROSSINI; SERRANI; WEIBEL; WAINFELD. Fútbol callejero: juventud, liderazgo y participación - trayectorias juveniles en organizaciones sociales de América Latina, 2012.

${ }^{8}$ ROSSINI et al. Fútbol callejero: juventud, liderazgo y participación, 2012.

9 "Supervalorização da competição e do elemento espetacular-visual costumeiro no âmbito do esporte de rendimento, vinculado ao interesse da exibição de performance para outrem ou de busca estética compulsiva ao aspecto físico massificado e padronizado pelos meios de comunicação, em detrimento da realização de práticas corporais autônomas e significativas, desenvolvidas pelo prazer desencadeado por elas mesmas, com satisfação pessoal intrínseca" (Rodrigues; Gonçalves Junior, 2009, p. 988).
} 
17, sub-20 - adulto) e ainda esportes adaptados. Ou seja, as pessoas sofrem diversas classificações para poderem praticar o esporte umas com as outras, valorizando-se em tal taxionomia, sobretudo, a suposta igualdade de condições para competir umas com as outras e não as possibilidades de aprendizagem entre os diferentes gêneros, interetária e entre pessoas com e sem deficiência.

A Fundación Fútbol para El Desarrollo (FuDe), localizada na cidade de Buenos Aires, na Argentina, organizou uma sistematização de suas experiências em 2012, no livro Fútbol callejero: juventud, liderazgo y partipación - trayectorias juveniles em organizaciones sociales de América Latina (2012), de Luciano Rossini e outros autores. A partir desse trabalho, posiciona-se o surgimento da prática callejera nas imediações de Moreno, em Buenos Aires, na Argentina, em meados de 1994, com a proposta de recuperar o espaço de protagonismo e diálogo entre os jovens, em um contexto onde a violência estrutural atravessava todas as relações pessoais na família, na escola, no bairro e nacomunidade. "El fútbol callejero fue concebido como una respuesta a las tantas crisis que afectan y atraviesan el "ser joven" en América Latina. Fútbol, para atraer la atención y vincular a los participantes desde una experiencia que recogiera sus intereses y gustos". ${ }^{10}$

No que diz respeito à metodologia, o fútbol callejero propõe regras que o torna diferente do futebol convencional, nas equipes meninas e meninos jogam juntos, não participam árbitros(as) e as partidas se dividem em três tempos. No primeiro tempo, as equipes estabelecem as regras do jogo em conjunto e de maneira consensual, no segundo tempo se joga a partida e no terceiro tempo, todos(as) os(as) jogadores(as) dialogam sobre o desenvolvimento do jogo e se houve respeito às regras acordadas mutuamente. Durante os três tempos o(a) mediador(a) participa facilitando o diálogo e a interação entre as equipes. ${ }^{11}$

Em uma partida de fútbol callejero não se ganha só fazendo mais gols, obtém-se a vitória por pontos, acordados no primeiro tempo de cada encontro, ou seja, há regras diferentes a cada partida e atribui-se a tais regras a pontuação desejada, na qual o gol deixa de ser a principal ferramenta para a vitória e com isso

\footnotetext{
${ }^{10}$ ROSSINI et al. Fútbol callejero: juventud, liderazgo y participación, 2012, p. 12.

${ }^{11}$ ROSSINI et al. Fútbol callejero: juventud, liderazgo y participación, 2012.
} 
o jogo se dá e se faz valer. ${ }^{12}$ Pelos três pilares do fútbol callejero: cooperação, respeito e solidariedade, ${ }^{13}$ que em nossa compreensão se relacionam com a pedagogia dialógica de Paulo Freire, ${ }^{14}$ pois, a partir das particularidades dessa prática, podemos utilizá-lo no processo de conscientização dos(as) envolvidos(as) de maneira dialógica, sem impor nada a ninguém e sim respeitando a cada um(a) que se lança a esse processo dialógico. É nesse contexto que se dá a figura do(a) mediador(a) no fútbol callejero, como facilitador(a) do diálogo, respeitando o espaço e o tempo das pessoas.

A prática da mediação é um espaço de aprendizagem soicioconstrutivo que visa a segurança, a confiança, o respeito, a solidariedade e a cooperação. Portanto, a mediação tem a finalidade de refletir coletivamente, resolver conflitos através de diálogo, promover a participação de todos(as) os(as) participantes. ${ }^{15}$

Entendemos a mediação como um espaço que permeia os três tempos da metodologia do fútbol callejero e não apenas no terceiro tempo. Como é a base que sustenta o jogo, necessita estar presente em todas as etapas. Logo, esta é a forma de entender o futebol com uma estratégia para criar e acompanhar processos de inclusão social, recuperar os valores humanos, valorizar e reconhecer reflexões das meninas e dos meninos e refletir sobre os processos educativos decorrentes dessa prática.

\section{Procedimentos Metodológicos}

O estudo foi realizado a partir de pesquisa de corte qualitativo, a qual não costuma se servir de instrumentos de coleta de informações que utilizam valores numéricos, ${ }^{16}$ além de que, em termos metodológicos, buscamos um enfoque que não se atenha a generalizações ou a neutralidade na pesquisa. ${ }^{17}$

\footnotetext{
${ }^{12}$ ROSSINI et al. Fútbol callejero: juventud, liderazgo y participación, 2012.

${ }^{13}$ VAROTTO; GONÇALVES JUNIOR; LEMOS. Fútbol callejero: processos educativos emergentes da prática social da mediação, 2017.

${ }^{14}$ FREIRE. Pedagogia da esperança: um reencontro com a pedagogia do oprimido, 2005.

${ }^{15} \mathrm{ROSSINI}$ et al. Fútbol callejero: juventud, liderazgo y participación, 2012.

${ }_{16}^{16}$ NEGRINE. Instrumentos de coleta de informações na pesquisa qualitativa, 1999.

17 ANDRÉ. Etnografia da prática escolar, 1995. MOLINA NETO; TRIVIÑOS. A pesquisa qualitativa na educação física: alternativas metodológicas, 1999.
} 
Durante a intervenção foram observados quatro encontros de uma turma do período das manhãs de quinta-feira, anotando todas as informações relevantes num diário de campo, que segundo Bogdan e Biklen (1994) "[...] é o relato escrito daquilo que o investigador ouve, vê, experiencia e pensa no decurso da recolha e reflectindo sobre os dados de um estudo qualitativo".18

Dessa forma foi descrito sistematicamente em diário de campo as relações entre educador(a) e educandos(as) e entre educandos e educandas nos encontros, para posteriormente analisar e refletir sobre as anotações decorrentes dos encontros de fútbol callejero.

Para estabelecer uma compreensão dos dados coletados e das anotações sistemáticas registradas em diários de campo, organizamos categorias temáticas. Segundo Gomes (1994):

As categorias são empregadas para se estabelecer classificações. Nesse sentido, trabalhar com elas significa agrupar elementos, ideias ou expressões em torno de um conceito capaz de abranger tudo isso [...] As categorias podem ser estabelecidas antes do trabalho de campo, na fase exploratória da pesquisa, ou a partir da coleta de dados. ${ }^{19}$

Assim, após diversas leituras dos registros do diário de campo, ao percebermos unidades significativas, estas foram agrupadas em categorias temáticas, organizadas a posteriori na matriz nomotética, de inspiração fenomenológica, objetivando movimento intencional em busca da essência do fenômeno pesquisado, possibilitando a construção dos resultados. ${ }^{20}$

\section{CONSTRUÇÃO DOS RESULTADOS}

Para a construção dos resultados foi fundamental a organização de uma Matriz Nomotética (Quadro 1), a qual permitiu melhor visualização das convergências e divergências encontradas no processo de busca da essência do fenômeno

\footnotetext{
${ }^{18}$ BOGDAN; BIKLEN. Notas de campo, p. 150.

19 GOMES. A análise de dados em pesquisa qualitativa, p. 70.

${ }^{20}$ MARTINS; BICUDO. A pesquisa qualitativa em psicologia: fundamentos e recursos básicos., 1989. GONÇALVES JUNIOR. Lazer e trabalho: a perspectiva dos líderes das centrais sindicais do Brasil e de Portugal em tempos de globalização, 2008. LEMOS. Entre o ócio e o negócio: possibilidades de desenvolvimento da motricidade escolar, 2013.
} 
vivenciado a partir da prática do fútbol callejero, resultando na construção de duas categorias, a saber: a) "Faustinho perguntou"; b) "Ah é bom porque aqui é o único lugar que não somos julgadas por não saber jogar, que nos dão atenção e nos ensinam".

\begin{tabular}{|c|c|c|c|c|}
\hline Categorias & $\begin{array}{l}1 \\
23 / 04\end{array}$ & $\begin{array}{l}11 \\
03 / 05\end{array}$ & $\begin{array}{l}\text { III } \\
08 / 05\end{array}$ & $\begin{array}{l}\text { IV } \\
21 / 05\end{array}$ \\
\hline A) "Faustinho perguntou" & $\begin{array}{l}4,6,7,11 \\
12,13,14 \\
15,16,21 \\
22\end{array}$ & $\begin{array}{l}1,2,3 d, 4,5, \\
6,7,8,9,10, \\
11,12,13, \\
14,15,16, \\
17,18,19, \\
20,21,22, \\
23,24\end{array}$ & $\begin{array}{l}1,2,3,4,5, \\
6,7,8,9,10 \\
11,12,13, \\
14,15,16, \\
17,18,19, \\
20,21,22\end{array}$ & $\begin{array}{l}1,2,3,4,5, \\
6\end{array}$ \\
\hline $\begin{array}{l}\text { B) "Ah é bom porque aqui é } \\
\text { o único lugar que não } \\
\text { somos julgadas por não } \\
\text { saber jogar, que nos dão } \\
\text { atenção e nos ensinam" }\end{array}$ & $\begin{array}{l}1,2,3,5,8 \\
9,10,17,18 \\
19,20,23\end{array}$ & & & $\begin{array}{l}7,8,9,10 \\
11,12,13 \\
14,15,16 \\
17,18\end{array}$ \\
\hline
\end{tabular}

Quadro 1: Matriz Nomotética.

Observamos que a matriz nomotética se compõe de uma coluna à esquerda na qual se expõe às categorias provenientes dos registros do diário de campo, enquanto no lado superior há disposição da identificação dos mesmos, representados com algarismos romanos em uma sequência horizontal, e no lado inferior, em algarismos arábicos, as unidades de significado encontradas, sendo que na ocorrência de "divergência" de compreensão referente àquela categoria por parte de algum dos(as) colaboradores(as) realizamos identificação com a letra "d" ao lado do número que representa a referida unidade de significado.

Nesta construção dos resultados, como sistema de notação, quando ocorrer transcrição de trecho referente a, por exemplo, Diário de Campo I, Unidade de Significado 03, apresentaremos a identificação I - 03. 


\section{a. "Faustinho perguntou"}

Esta categoria emergiu a partir da análise das unidades de significado, destacadas dos diários de campo e foi possível perceber o quão importante é a figura do(a) mediador(a) no fútbol callejero. No decorrer dos encontros, Faustinho, educador que atua no projeto de extensão VADL-MQF, desenvolveu a função da mediação social. ${ }^{21}$ Esse processo se inicia a partir de seu posicionamento, a fim de situar os(as) participantes acerca das ocorrências do jogo:

Faustinho perguntou se estávamos bem e todos(as) disseram que sim e ele seguiu dizendo: "O segundo tempo terminou em gols, um para cada equipe, o que resulta em um ponto para cada equipe, as duas equipes comemoraram os gols e, pela regra criada no primeiro tempo, cada equipe computa dois pontos, por todos(as) terem comemorado os gols, com isso, neste momento cada equipe tem três pontos" (I-15).

O educador Faustinho lembrou os(as) participantes de uma regra, aparentemente corriqueira a eles(as), as pessoas que tem menos experiência com a bola nos pés ao recebê-la, dar o tempo que ela necessita para fazer sua jogada e todo(as) concordaram com mais esta regra (I - 06).

Antes de darmos início ao segundo tempo, o educador Faustinho perguntou quantos pontos teria cada pilar, Vitória logo se manifestou e disse: "Acho melhor dois pontos cada", os(as) demais concordaram (I - 07).

Atuar como mediador(a) de fútbol callejero requer ações que incluam as pessoas no jogo e muitas dessas ações dizem respeito às experiências dos(as) participantes com a bola nos pés. A partir disso, faz-se necessário algumas estratégias, conforme o seguinte:

$\mathrm{Eu}^{22}$ e Faustinho combinamos de ir parando o jogo quando necessário, a fim de orientar as pessoas sobre posicionamento e possíveis ações no jogo, assim, acreditamos que possa ajudar as pessoas com menos experiência em jogos coletivos que demandam estratégias de ocupação de espaço e sair da marcação da outra equipe (I - 11).

21 VAROTTO; GONÇALVES JUNIOR; LEMOS. Fútbol callejero, 2017. VAROTTO; LEMOS. Compreensões sobre o processo de formação de mediadores(as) no fútbol callejero, 2017.

${ }^{22}$ A partir da discussão dos resultados todas as vezes que o "Eu" aparece se trata do pesquisador Nathan que atuou em conjunto com o educador Faustinho. Vale ressaltar que há outro educador que também se chama Natan, neste caso, no texto aparecerá "Natan". 
[...] Vasilina estava com a bola no meio da quadra e duas pessoas da equipe verde chegaram perto dele, com a intenção de marcar e recuperar a bola. Pedimos que interrompessem a jogada e perguntamos para Vitória, companheira de equipe de Vasilina, qual o melhor lugar para ela receber a bola naquele momento, visto que ela estava entre as pessoas da equipe verde (que tentavam recuperar a posse de bola) e havia um espaço sem ninguém ocupando com possibilidades de ela receber a bola. Faustinho perguntou: "Vitória, observe a jogada, você acha que onde você está é possível de receber a bola?", ela respondeu: "Não sei" (ao final desta fala ela riu), Faustinho disse: "Não há problemas você não saber, por isso estamos fazendo isso, atrás de você tem um espaço livre, se você se posicionar ali e de frente para o gol, a possibilidade de recepção da bola e muito grande". Ela ocupou o espaço sugerido por Faustinho (I-13).

O fútbol callejero preza por três pilares, a saber, respeito, cooperação e solidariedade, estes, fazem a diferença no jogo em olhar, considerar, respeitar outrem, porém esses valores, tem de estar presentes em todos os âmbitos de nossas vidas, extrapolando as linhas da quadra. A partir disso, surge a proposição:

Enquanto Brock Lesnar relatava sobre o motivo de a equipe em que ele fazia parte pontuar em solidariedade eu estava pensando em como fazer com que nós pudéssemos por em prática as vivências com o fútbol callejero fora daquele contexto, porém, em outros âmbitos da vida. Foi então que me motivei e pedi a palavra e disse: "O que vocês acham de nós levarmos o que vivenciamos aqui para nossa casa, escola e em outros lugares em que frequentamos, pondo em prática atitudes respeitosas, solidárias e cooperativas e no próximo encontro cada um(a) expõe o que aconteceu e como foi vivenciar isso?". Sinceramente achei que haveria resistência da parte dos(as) participantes em aceitar e para minha surpresa, todos(as) aceitaram. Fiquei muito feliz, pois penso que a metodologia do fútbol callejero é para ser vivenciada no dia a dia, em todas as situações e esta foi a primeira vez que, talvez tenha conseguido aliar, com os(as) participantes, esses aspectos para além das linhas da quadra. Nas experiências anteriores, sentia-me limitado aos encontros, que penso ser o ponto de partida para vislumbrarmos a incorporação desses valores no cotidiano (I - 21).

No encontro posterior a essa proposição os(as) participantes relataram suas vivências:

Ainda restava um tempo e eu perguntei quem se lembrou do desafio proposto do último encontro, neste encontro havia pessoas que não estavam presentes quando foi sugerido este desafio, que é: Vivenciar os pilares do fútbol callejero fora do ambiente do projeto, ou seja, na escola, em casa e nos demais ambientes em que vivemos. Porém é muito válido qualquer valor, por exemplo, honestidade, lealdade, etc. (II - 21). 
Vasilina pediu a palavra e disse: "Eu não fiz nada, eu só fiquei em casa esses dias, dormia, jogava vídeo game e só". Intrigado com o que acabara de falar, indaguei: "Mas como não fez nada? E na escola?", e ele prosseguiu "Não vou à escola". Eu estava espantado, pois ele tem 14 anos, então perguntei: "Por que você não vai à escola?", e ele respondeu: "Minha mãe não achou vaga e ela voltou para São Paulo e, por enquanto, estou na casa do Henrique, mas vou voltar para São Paulo, ainda tem móveis aqui, minha mãe vai voltar para pegar e aí volto com ela". Eu disse: "Onde você mora aqui? Tem que ter vaga, se você quiser eu posso te ajudar a encontrar uma vaga em uma escola que fique próximo à sua casa”. Ele me disse: "Logo eu volto para São Paulo, lá minha mãe vai me matricular em uma escola" (II - 23).

Senti no olhar dele a esperança de que em São Paulo a probabilidade é alta de sua mãe conseguir um emprego e eles poderem viver juntos. Pois ele me disse que está há dois anos em São Carlos e neste tempo, sua mãe não conseguiu um trabalho, por isso ela decidiu voltar para São Paulo, almejando dias melhores (II - 24).

Situações como a relatada e vivenciada no excerto anterior nos mostram que a partir do diálogo, no pleno desenvolvimento de uma relação humana empática é possível conhecer e saber da vida de outra pessoa, daí nos oferecer para ajudar e nos mostrar solidários àquele momento a fim de buscarmos estarsendo-com-outrem, tendo em vista o ser mais.

É comum chegar participantes que nunca vivenciaram o jogo e outros(as) que vivenciaram uma ou duas vezes e não se lembram da dinâmica, por isso é importante situar essas pessoas desde o contexto histórico até os modos de jogar:

Faustinho começou dizendo: "Bom, antes de iniciarmos a construção das regras, temos dois participantes que já participaram uma vez, então vou relembrar como funciona o callejero". E prosseguiu: "Este jogo é composto por três tempos, no primeiro construímos as regras do jogo, no segundo rolamos a bola para jogar a partir das regras criadas e estabelecidas e no terceiro tempo, nos sentamos em roda para dialogar sobre as ocorrências do jogo. Esta prática é balizada por respeito, cooperação e solidariedade e não há árbitro, há um mediador que fica responsável por descrever as regras criadas e facilitar o diálogo no terceiro tempo". A partir do que foi dito por Faustinho, os participantes rememoraram a dinâmica do jogo e sugeriram de iniciarmos a construção das regras (II - 01).

Antes disso, interferi dizendo: "Creio ser relevante contextualizar o porquê falamos fútbol callejero e não futebol de rua". Continuei: "O fútbol callejero foi criando e pensado na Argentina em meados de 1994, no bairro empobrecido de Moreno, na cidade de Buenos Aires, o 
propositor é ex-jogador de futebol e naquele momento a região de Moreno enfrentava briga de gangues, violência familiar, desvalorização dos(as) jovens e a partir deste contexto pensou e estruturou esta prática". No Brasil, quando mencionamos futebol de rua, nos remete a jogos que fazem alusão a um rolar de bola, sem que ao final, se dialogue sobre o que, ali, aconteceu, por isso preferimos manter o nome em espanhol, pelo contexto em que foi criado (II - 02).

Há também situações adversas e, algumas vezes, desinteresse por parte de componentes que participam há mais tempo. No momento de retomar informações já conhecidas, eles assumem uma postura que dificulta o andamento da atividade: "Percebi que Bryan não queria saber do contexto e não estava atento ao que se falava e por isso começou a tirar a atenção de João, juntou um punhado de folhas, que havia caído de uma árvore e estava no chão, e jogou em João, ele não revidou e nem se queixou de Bryan" (II - 03).

0 papel do(a) mediador(a) é fundamental, pois em diferentes momentos faz-se necessário o uso de estratégias educativas com o intuito de construir os processos educativos em conjunto:

Ao chegarmos à quadra nos sentamos em roda e Faustinho, que desde o início das minhas inserções é quem faz o papel do mediador, disse: “Galera, vocês já aprenderam algo apenas olhando?", e José respondeu: "Ah, eu aprendi a fazer embaixadinha olhando e também aprendi alguns dribles, às vezes vejo vídeos no celular de alguns jogadores fazendo dribles e depois tento fazer a partir do que vi" (III-01).

Faustinho continuou: "Muito legal, perguntei isso porque, ao menos para mim, é difícil entender o futsal, pois este jogo tem uma dinâmica diferente do futebol. Então proponho de no próximo encontro, juntos, vermos alguns lances e jogadas do futsal, a fim de aprendermos algumas particularidades desse esporte, por exemplo, tática de jogo e movimentação, o que vocês acham?", e os(as) participantes concordaram (III-02).

Esta categoria trouxe elementos que estão aderidos às ações que o(a) mediador(a) de fútbol callejero desenvolve e constrói ao longo dos encontros, sempre, tendo em vista que os(as) protagonistas são as crianças e os jovens. 0 termo mediador(a) não é por acaso, pois essa pessoa irá mediar os diferentes momentos, tendo em vista que não há uma forma e/ou uma receita precisas, pois há corpos que criam situações, muitas vezes tensas. Sendo assim, o(a) mediador(a) 
convidará a todos(as) os(as) envolvidos(as) a procurar uma solução por meio do diálogo. Portanto, essa categoria faz menção ao mediador, apontando, a partir dos fragmentos retirados dos diários de campos, as tramas situacionais dos encontros.

\section{b. “Ah é bom porque aqui é o único lugar que não somos julgadas por não saber jogar, que nos dão atenção e nos ensinam"}

O título desta categoria é a fala de uma participante que expressa seu pensamento no momento da mediação em que o mediador questiona os(as) participantes se gostaram das orientações dadas ao longo do segundo tempo, pois íamos parando as jogadas a fim de dialogar sobre as possibilidades de movimentação em quadra: “Perguntei aos(às) participantes o que acharam dos momentos em que paramos o jogo e, principalmente as meninas, gostaram. Laraliz disse: "Ah é bom porque aqui é o único lugar que não somos julgadas por não saber jogar e que nos dão atenção e nos ensinam" (I-20).

Em determinados acontecimentos, precisamos agir com calma e com cuidado, a fim de explicar como se joga:

O jogo seguia bem, em um momento Ester se lançou na bola e pegou-a com a mão, havia muitas pessoas perto da bola, mais meninos, de uma maneira ríspida os meninos disseram que não era para ela pegar a bola com a mão, vi que ela estava ficando assustada, pois Ester tem apenas seis anos de idade, me dirigi até ela, agachei e olhando em seu olho disse: "Ester, no futebol só quem pode pegar a bola com a mão é o goleiro, os outros jogadores só podem utilizar o pé e o que você fez é arriscado, pois como as jogadas são rápidas, você poderia ter se machucado, porque alguém iria tentar chutar a bola, tudo bem?". Ela, ainda, estava meio assustada, mas entendeu o que eu lhe disse e continuou a jogar (IV-07).

A troca de experiências entre as pessoas coadunam com os diálogos em que possibilitam um(a) e outro(a) a aprender com este(a) ou com aquele(a):

Ao final da roda fui ao encontro de Faustinho e perguntei o que ele estava achando e ele disse: "Está sendo muito bom você participar, pois eu sigo com meu jeito, pois, sinto muita dificuldade em tratar alguns assuntos e acontecimentos e aliar aspectos educativos e as suas falas me ajudam muito com isso, está sendo um grande aprendizado pra mim", respondi dizendo: "Nossa, fico muito feliz em ouvir isso, saiba que 
mesmo depois que terminar esta inserção você pode contar comigo para o que precisar, será um prazer poder contribuir"(I-23).

É difícil saber o que irá acontecer no decorrer dos dias, sempre imaginamos o melhor, porém, quando algo sai diferente do que estimamos, há de se vivenciar com o maior carinho e amor possível. Em minha última inserção, algo não previsto aconteceu:

[...] o educador Gustavo chutou a bola que acertou no abdômen de Djon, o menino caiu no chão e ficou parado, imóvel. Eu ouvi alguém dizendo que ele tem asma, me aproximei dele, chamei e ele não tinha força para se levantar, o peguei em meus braços e pedi para o educador Natan pegar a bombinha dele. Com muita dificuldade, Djon disse a cor da sua bolsa e então o educador saiu correndo. Com ele em meus braços saí da quadra de areia e fui caminhando ao encontro de Natan. Faustinho ficou com o restante dos(as) participantes na quadra e deu seguimento ao jogo (IV-08).

A partir do episódio exposto, uma rede de pessoas, sensibilizadas com o que havia ocorrido, mobilizou-se:

Quando eu estava saindo da quadra com Djon vi o educador Murilo correndo em direção ao local onde as crianças deixam suas bolsas, pois ele (Murilo) viu o que havia acontecido e estava mais perto deste lugar. Gustavo caminhava ao meu lado e pedi para que ele fosse ao encontro de Natan a fim de solicitar que ele fosse mais rápido (IV-09).

Natan chegou com a bombinha, Djon pegou-a de minha mão e pressionou para que o composto fosse para sua boca a fim de aliviar a falta de ar. Eu o via fazer a contagem dos segundos, com os dedos, para que pudessem aspirar novamente o composto. Aos poucos ele foi se reestabelecendo e conseguiu ficar em pé (IV-11).

Com a situação mais amena, a primeira reação foi de comunicar algum responsável do menino, porém, ele disse:

"Não liga para minha mãe, eu mesmo vou contar para ela, porque senão ela vai me tirar do esporte e eu não quero isso", foi um momento angustiante, pois como pai sentia que eu tinha de ligar, mas o modo como ele falou que poderia interromper a participação no projeto me deixou balançado e então, ao menos naquele momento, decidi não ligar (IV-14). 
Porém ao final das atividades: “[...] Murilo, coordenador adjunto do projeto, ligou para a mãe de Djon a fim de dizer o que havia ocorrido e constatou que ele já havia relatado o caso a ela e estava tudo bem" (IV-17).

Esta categoria traz reflexões em torno do estar junto, que envolve muitas vezes situações adversas, mas, com as pessoas se disponibilizando a ajudar, há uma maior possibilidade de desenvolvimento dos sentimentos de segurança e confiança, em situações de jogo e em outras situações mais complexas.

\section{CONSIDERAÇõES FINAIS}

Ao modo da perspectiva qualitativa de pesquisa realizamos o movimento de "dar voltas" ao entorno do fenômeno investigado e com base nos dados em campo e no referencial teórico, que a compreensão da metodologia proposta no fútbol callejero envolve um processo, a experiência da vivência. É comum entre as pessoas que jogam pela primeira vez imaginarem que se trata apenas de um nome diferente, com regras diferentes, para praticar o futebol convencional, geralmente visto nas partidas dos campeonatos televisionados, ou seja, em que prevalece a competição entre uma equipe e outra ao invés de relações cooperativas, respeitosas e solidárias, conforme preconizam os três pilares do fútbol callejero, como visto em Luciano Rossini. ${ }^{23}$

Assim, na dialogicidade apontada por Paulo Freire (2005, 2013), que entendemos ser fortalecedora das proposições da metodologia do fútbol callejero, segundo Rossini, o diálogo-reflexão coletivo sobre a importância ou não do gol, sobre a derrota e a vitória, sobre competição e cooperação, sobre a possibilidade de meninas e meninos compartilharem o mesmo campo de jogo, vai tendo cada vez mais espaço. Por meio dessa estratégia, também cresce o exercício crítico, que envolve tensão, mas ao mesmo tempo a possibilidade de superar preconcepções.

Ressaltamos ainda que o caminho não é fácil, pois há conflitos, discussões, divergências, elementos presentes em um processo dialógico e dialético. Daí, inclusive, a construção da categoria "Faustinho perguntou". Na experiência pessoal do

${ }^{23}$ ROSSINI et al. Fútbol callejero: juventud, liderazgo y participación, 2012. 
mediador, foi fundamental exercer afastamento necessário para intermediar os diálogos sem interromper os(as) participantes com soluções potencialmente mais rápidas, porém oriundas das minhas experiências, quando o que se visa é a construção dialógica deles e delas. 0 processo envolveu uma educação da escuta, mais do que da fala, evitando, roubar a palavra de outrem.

Entrelaçada a essa categoria está, como não poderia deixar de ser, a categoria "Ah é bom porque aqui é o único lugar que não somos julgadas por não saber jogar, que nos dão atenção e nos ensinam", em que vimos pouco a pouco serem construídas relações mais sólidas a partir dos três pilares do fútbol callejero: cooperação, respeito e solidariedade. Esses pilares, que podemos denominar de processos educativos, desejados pela metodologia do fútbol callejero, em construção, enfrentam valores distintos, despejados pelos meios de comunicação em nosso cotidiano, inclusive através do esporte mais difundido no Brasil, o futebol. Mas somente ao tensionar os valores midiáticos relacionados à primazia da competição, da vitória a qualquer preço, presentes na reprodução do futebol, pela experiência da produção/criação/fruição de uma prática dialógica é que podemos enfrentá-los e possibilitar o surgimento de outros valores.

Como vimos, a mediação do terceiro tempo, previsto na metodologia do fútbol callejero, promove o encontro das consciências e a possibilidade da compreensão das situações pelo diálogo, em que cada um(a) pode se expressar e apresentar suas próprias versões das ocorrências, de modo coletivo, em que os(as) demais podem também opinar sobre suas percepções, buscando consenso e favorecendo amadurecimentos de todos(as) para o exercício crítico da cidadania.

Destacamos também minha experiência passando pela mediação nas práticas do fútbol callejero, bem como pela coleta e análise de dados que ora finalizamos, possibilitando inúmeras aprendizagens: escutar mais; valorizar o saber advindo da experiência de cada um(a) dos(as) participantes e educadores(as); ser paciente com a construção da autonomia de cada participante, condição indispensável; e perceber que ao educar, educo-me.

Consideramos, com isso, que o fútbol callejero não é apenas um jogo, é uma práxis educativa que estabelece interfaces com o jogo/lazer com potencialidades 
para nos ensinar a ser mais, a refletir criticamente acerca de nossa ação com os outros e com mundo, desafiando-nos a construir coletivamente uma convivência acolhedora, inclusiva e solidária, na qual o diálogo é a base das relações estabelecidas entre todos os participantes.

\section{REFERÊNCIAS}

ANDRÉ, Marli E. D. A. Etnografia da prática escolar. Campinas: Papirus, 1995. BICUDO, Maria A. V.; ESPÓSITO, Vitória H. C. Pesquisa qualitativa em educação. São Paulo: UNIMEP, 1997.

BOGDAN, Roberto; BIKLEN, Sara. Notas de campo. In: Investigação qualitativa em educação: uma introdução à teoria e aos métodos. Porto: Porto Editora, 1994, p. 150-175.

FREIRE, Paulo. Pedagogia da esperança: um reencontro com a pedagogia do oprimido. Rio de Janeiro: Paz e Terra, 2005.

FREIRE, Paulo. Pedagogia do oprimido. Rio de Janeiro: Paz e Terra, 2013.

GOMES, Romeu. A análise de dados em pesquisa qualitativa. In: MYNAIO, Maria Cecília de Souza. (Org.). Pesquisa Social: teoria, método e criatividade. Petrópolis: Vozes, 1994.

GONÇALVES JUNIOR, Luiz; CARMO, Clayton da S.; CORRÊA, Denise A. Cicloviagem, lazer e educação ambiental: processos educativos vivenciados na Serra da Canastra. Licere, Belo Horizonte, v. 18, n. 4 p. 173-208, 2015.

GONÇALVES JUNIOR, Luiz. Edital de atividades de extensão - Vivências em Atividades Diversificadas de Lazer. São Carlos: ProEx/UFSCar, 2013.

GONÇALVES JUNIOR, Luiz. Lazer e trabalho: a perspectiva dos líderes das centrais sindicais do Brasil e de Portugal em tempos de globalização. In: . (Org.). Interfaces do lazer: educação, trabalho e urbanização. São Paulo: Casa do Novo Autor, 2008, p. 54-108.

LEMOS, Fábio R. M. Entre o ócio e o negócio: possibilidades de desenvolvimento da motricidade escolar. Tese (Doutorado em Educação). Universidade Federal de São Carlos, 2013.

MARCELLINO, Nelson C. Lazer e educação. Campinas: Papirus, 2000.

MARTINS, Joel; BICUDO, Maria A. V. A pesquisa qualitativa em psicologia: fundamentos e recursos básicos. São Paulo: Moraes/EDUC, 1989. 
MOLINA NETO, Vicente; TRIVIÑOS, Augusto. N. S. (Orgs.). A pesquisa qualitativa na educação física: alternativas metodológicas. Porto Alegre: Ed. Universidade/UFRGS/Sulina, 1999, p. 61-93.

NEGRINE, Airton. Instrumentos de coleta de informações na pesquisa qualitativa. In: MOLINA NETO, Vicente; TRIVIÑOS, A. N. S. (Orgs.). A pesquisa qualitativa na educação física: alternativas metodológicas. Porto Alegre: Ed. Universidade/UFRGS/ Sulina, 1999, p. 61-93.

RODRIGUES, Cae; GONÇALVES JUNIOR, Luiz. Ecomotricidade: sinergia entre educação ambiental, motricidade humana e pedagogia dialógica. Motriz, Rio Claro, v. 15, n. 4, p. 987-995, 2009.

ROSSINI, Luciano; SERRANI, Esteban; WEIBEL, Matías; WAINFELD, Manuel. Fútbol callejero: juventud, liderazgo y participación - trayectorias juveniles en organizaciones sociales de América Latina. Buenos Aires: FUDE, 2012.

SANTOS, Matheus $O$. Ludicidade, animação cultural e educação: um olhar para o projeto "Vivências em Atividades Diversificadas de Lazer". Dissertação (Mestrado em Educação), Universidade Federal de São Carlos, 2008.

VAROTTO, Nathan. R.; GONÇALVES JUNIOR, Luiz.; LEMOS, Fábio. R. M. Fútbol callejero: processos educativos emergentes da prática social da mediação. Revista Kinesis, Santa Maria, v. 35, n. 3, p. 91-100, set.-dez. 2017.

VAROTTO, Nathan R.; LEMOS, Fábio R. M. Compreensões sobre o processo de formação de mediadores(as) no fútbol callejero. Anais do Colóquio de Pesquisa Qualitativa em Motricidade Humana: Ecomotricidade e bem viver, Aracaju; São Cristóvão. São Carlos: SPQMH, 2017, p. 308-319. 